\title{
Momordica charantia nanoparticles promote mitochondria biogenesis in the pancreas of diabetic-induced rats: gene expression study
}

\author{
Olusola Olalekan Elekofehinti* (i), Olusola Christianah Ayodele and Opeyemi Iwaloye
}

\begin{abstract}
Background: Mitochondria dysfunction is one of the clinical features of diabetes mellitus (DM), which is a hallmark of insulin resistance (IR). This study investigates the therapeutic effect of Momordica charantia nanoparticles on mitochondria biogenesis in diabetic-induced rats. Forty-two adult wistar rats (average weight of 189 \pm 10.32 ) were grouped as follows: STZ (65 mg/kg), control group, STZ + silver nitrate (10 mg/kg), STZ + M. charantia silver nanoparticles (50 mg/kg), STZ + metformin (100 mg/kg), and STZ + M. charantia aqueous extract ( $100 \mathrm{mg} / \mathrm{kg})$. DM was induced intraperitoneal using freshly prepared solution of STZ (65 mg/kg), and rats with fasting blood sugar (FBS) above $250 \mathrm{mg} / \mathrm{dl}$ after $72 \mathrm{~h}$ of induction were considered diabetic. Treatment started after the third day of induction and lasted for 11 days. Effect of $M$. charantia nanoparticles on glucose level and pancreatic expression of genes involved in mitochondria biogenesis (PGC-1a, AMPK, GSK-33, PPAR ), inflammation (IL-1B, TNFa) and glucose sensitivity (PI3K, AKT, PTEN Insulin and Glut2) were quantified using reverse-transcriptase polymerase chain reaction (RT-PCR).

Results: The results showed that M. charantia nanoparticles promote mitochondria biogenesis, glucose sensitivity and reverse inflammation in the pancreas of diabetes rat model through upregulation of PGC-1a, AMPK, PPART, AKT, Insulin and Glut2 mRNA expression and downregulation of GSK-3ß, PI3K, L-1B and TNFa mRNA expression in the pancreas of diabetic rats.
\end{abstract}

Conclusion: This study thus concludes that $M$. charantia nanoparticles may provide effective therapeutics against mitochondria dysfunction in the pancreas of diabetic model.

Keywords: Diabetes mellitus, Mitochondria biogenesis, Inflammation, Glucose sensitivity, Momordica charantia nanoparticles

\section{Background}

For many decades, research on finding cure or effective therapies for a number of metabolic diseases have been implemented and executed. Despite rapid advances in technologies to improve the conventional treatment of these groups of diseases, there seems no end in sight for permanent cure of these diseases. Diabetes mellitus (DM) is the most popular health condition among the groups of metabolic diseases, and it has emerged as one

*Correspondence: ooelekofehinti@futa.edu.ng

Bioinformatics and Molecular Biology Unit, Department of Biochemistry,

Federal University of Technology Akure, Akure, Ondo State, Nigeria of the global leading cause of health concern $[1,2]$. With each passing decade, global record of people living with diabetes indicated that the number has been increasing geometrically $[3,4]$. The functional changes that accompany diabetes are either insufficient release of insulin from pancreatic beta cells or poor response of the cells to the effects of insulin [5]. These pathophysiological conditions could triggers tens of complications on the long-term if left untreated. Several molecular pathways underlying DM and its complications have been studied, explored and elucidated, no available satisfactory effective therapy, however, has been found to slow down or revert the pathogenesis of diabetes [6]. 
Mitochondria are double-membrane bound organelles found in abundance in most of eukaryotic organisms, and they play several critical roles in metabolism [7]. In humans, their catabolic roles include oxidation of pyruvate, fats, proteins, etc. As well as their extensive documented anabolic roles in delivering chain of carbon atoms for the synthesis of sugar, amino acids, fatty acids and other biomolecules [8]. Mitochondria biogenesis is a cellular process involving the production of new mitochondria. Due to the high versatility of mitochondria to change their morphology through fission and fussion events, these series of dynamic events permit mitochondrial network to spontaneously remodel itself $[9,10]$.

The peroxisome proliferator-activated receptor gamma coactivator 1 alpha (PGC-1 $\alpha)$ is known as the core orchestration of mitochondria biogenesis in the context of energy demand [11]. It is implicated in a number of signaling pathways that accentuate all reactions involved in ATP generation from nutrients in response to physiological conditions, promoting adaptation to increased energy demand [12]. PGC- $1 \alpha$ coordinates mass mitochondrial production through stimulation of nuclear respiratory factor 1 (Nrf1) and nuclear respiratory factor 2 (Nrf2). This ensures coordination between proteins produced within and outside the mitochondria needed for biogenesis, activation of estrogen-related receptor alpha $(E R R \alpha)$ for high capacity to breakdown fatty acid ( $\beta$-oxidation). Other signaling molecules such as glycogen kinase $3 \beta$, peroxisome proliferator-activated receptor- $\Upsilon$ (PPAR $\Upsilon$ ), and AMP-activated protein kinase (AMPK) are known to play major contribution to functioning of the mitochondria [13].

Insulin resistance is an important feature of type II diabetes mellitus (T2DM). The underlying mechanism of insulin resistance, however remains vague but may involve pathological chances in multiple tissues including pancreas. Loss of mitochondria functions has been implicated in the development of insulin resistance [14]. Compelling evidence suggests that boosting mitochondrial function may represent a valuable therapeutic tool to improve insulin sensitivity $[14,15]$. Scientific investigation on the effects of herbal plants and dietary supplements in mitochondria function have been executed, and the reports showed that they support increased mitochondria number or mass [16-18]. In spite of the promising effects of these plants on mitochondria biogenesis as rationale for T2DM treatment, there is no FDA approved drug for improving mitochondria function. Hence, this study explored the effect of Momordica charantia nanoparticles on pancreas mitochondria biogenesis in STZ-induced rats. In addition to this, the anti-inflammatory and glucose modulating effects of the plant nanoparticles in the rats' pancreatic tissue were also taken into consideration. In our previous study, we demonstrated that $M$. charantia nanoparticles $(50 \mathrm{mg} / \mathrm{kg})$ slowed down the progression of diabetic nephropathy through JAK/STAT and AKT/ PI3K pathways [19]. Although studies have provided the hypoglycemic and antidiabetic properties of different $M$. charantia under in vivo and in vitro conditions [20,21], no available study has deployed the use of nanoparticles to deliver $M$. charantia into biological system. From our previous study, we have acquired the background knowledge that $M$. charantia nanoparticles at lower dosage $(50 \mathrm{mg} / \mathrm{kg}$ ) reduce blood sugar level in STZ-induced diabetic rats than the plant extract. This study will unravel new therapeutic effect of $M$. charantia nanoparticles in boosting mitochondrial biogenesis and function in diabetic rats.

\section{Methods}

\section{Collection of plant material and authentication}

One kilogram $(1 \mathrm{~kg})$ of matured $M$. charantia leaves was collected fresh from the vicinity of Academic Building, School of Sciences (SOS), Federal University of Technology Akure (FUTA), Ondo State, and the plant sample was authenticated with voucher number: FUTA/BIO/0125.

\section{Preparation and methanolic extraction of the plant}

The leaves were washed with distilled water, before airdrying for 9 days. The leaves were dehydrated in the oven at $40{ }^{\circ} \mathrm{C}$ for $3 \mathrm{~h}$. The dried leaves were ground to powdered form using an electric blender. A weight of $250 \mathrm{mg}$ was measured from the powdered form of $M$. charantia and dissolved in $1250 \mathrm{ml}$ of ethanol; it was allowed to stand for $48 \mathrm{~h}$ and filtrated. The filtrate was dried using rotary evaporator to obtain a methanolic extract of $M$. charantia leaves.

\section{M. charantia nanoparticles synthesis from silver nitrate solution}

The modified method described by Nahar et al. [22] was adopted to synthesize the bitter melon nanoparticles. The freeze dried $M$. charantia methanolic extract were dissolved in $1 \mathrm{mM}$ aqueous silver nitrate solution at ratio 1 : $9(\mathrm{v} / \mathrm{v})$, and allowed to stand for $24 \mathrm{~h}$. A solution undergo a change in color (from dark green into light brown) to demonstrate the formation of nanoparticles. The bioreduction of $\mathrm{Ag}^{+}$ions to $\mathrm{Ag}^{0}$ was monitored using a UVVis spectrophotometer. To enhance the stability and reduce the reactivity of the newly synthesized $M$. charantia nanoparticles, the solution of the nanoparticles was freeze-dried and stored at room temperature $\left(25^{\circ} \mathrm{C}\right)$ [23]. 


\section{Animal purchase, experimental design, grouping and treatment}

For the purpose of the present study, 42 male Wistar rats (average weight of $189 \pm 10.32$ ), aged 8 to 9 weeks old, were purchased from the rat breeding colony of Department of Biochemistry, School of Sciences (SOS), Federal University of Technology Akure, Nigeria and housed in the Departmental animal house at $25{ }^{\circ} \mathrm{C}$ with a $12 \mathrm{~h}$ light-dark cycle. The experimental animals were given access to animal feeds and distilled water ad libitum. Before the commencement of the experimental study, an ethical approval was collected from Animal Welfare and Research Ethics Committee at the Federal University of Technology Akure, Nigeria. The rats were acclimatized for two weeks after which the animals were sorted into 6 different groups of 7 rats each. DM was induced by intraperitoneal (i.p) injection of freshly buffered (0.1 M citrate, $\mathrm{pH} 4.5)$ solution of STZ (65 $\mathrm{mg} / \mathrm{kg}$ ) to overnight fasted rats. The fasting blood sugar (FBS) of the rats was taken before STZ induction and after $72 \mathrm{~h}$ of DM induction, and rats with $\mathrm{FBS} \geq 250 \mathrm{mg} / \mathrm{dl}$ were considered diabetic. There was no mortality after the STZ induction. The animal groups are as follows:

- Group 1: STZ (65 mg/kg)

- Group 2: Control group

- Group 3: STZ (65 mg/kg) + silver nitrate (10 mg/kg)

- Group 4: STZ (65 mg/kg) + M. charantia silver nanoparticles $(50 \mathrm{mg} / \mathrm{kg})$

- Group 5: STZ (65 mg/kg) + metformin (100 mg/kg)

- Group 6: STZ (65 mg/kg) +M. charantia aqueous extract $(100 \mathrm{mg} / \mathrm{kg})$

The treatments were given to the rats via oral gavage. The treatment of STZ induced rats lasted for 11 days after which sacrifices were made on the $12^{\text {th }}$ day. The pancreatic tissue of the rats was collected and preserved in Trizol reagent.

\section{Isolation and purification of total RNA}

The Trizol-preserved pancreatic tissues were homogenized in an eppendorf tube using plastic pestle to permit thorough exposure of the cell's nucleus. The homogenized tissues were partitioned using chloroform as gradient separation medium. Isoamy alcohol was added as precipitating solution, after which the sample was treated with DNase (NEB) for 10 min before the RNA pellet was washed with ethanol to remove any DNA and phenol contamination, respectively. The obtained DNase free RNA was suspended in nuclease-free water. The purity was determined by measuring the absorbance at 260 and $280 \mathrm{~nm}$, respectively [24].

\section{CDNA synthesis: polymerase chain reaction (PCR) and amplification of gene of interest}

The obtained total RNA was converted to complementary DNA (cDNA) using reverse transcriptase polymerase chain reaction (RT-PCR). The enzyme reverse transcriptase initiated the conversation of the RNA to cDNA [24]. After synthesis of the cDNA, the genes of interest were amplified using designed and optimized set of primers (see Table 1), which comprised forward and reverse primers. The PCR Master Mix catalyzes the amplification using thermocylcer (Eppendorf Mastercycler AG 22,331) Hamburg for 30 cycles.

\section{Agarose gel electrophoresis}

The amplicons from RT-PCR products were subjected to $1 \%$ agarose gel electrophoresis to enable the migration of the amplicons from the anode to the cathode at constant voltage. The relative density and intensity of the gene bands were quantified using Image J software.

Table 1 List of designed, optimized and synthesized primers specific for each gene

\begin{tabular}{lll}
\hline Gene name & Forward primer & Reverse primer \\
\hline IL-1B & GCAATGGTCGGGACATAGTT & AGACCTGACTTGGCAGAGGA \\
TNF Alpha & ACCACGCTCTTCTGTCTACTG & CTTGGTGGTTTGCTACGAC \\
PGC-1 Alpha & TTCAGGAGCTGGATGGCTTG & GGGCAGCACACTCTATGTCA \\
Insulin rats & GTCCTCTGGGAGCCCAAG & ACAGAGCCTCCACCAGG \\
Glucokinase & GTGTACAAGCTGCACCCGA & CAGCATGCAAGCCTTCTTG \\
AMPK & ATCCGCAGAGAGATCCAGAA & CGTCGACTCTCCTTTTCGTC \\
Gsk3b & GGGACAGTGGTGTGATCAG & GCCGAAAGACCTTCGTCCAA \\
Glut2 & TAGTCAGATTGCTGGCCTCAGCTT & TTGCCCTGACTTCCTCTTCCAAC \\
PI3K & AACACAGAAGACCAATACTC & TTCGCCATCTACCACTAC \\
AKT & TCACCTCTGAGACCGACACC & ACTGGCTGAGTAGGAGAACTGG \\
PTEN & CCCACCACAGCTAGAAACTTATC & CGTCCTTTCCCAGCTTTACA \\
\hline
\end{tabular}




\section{Statistical analysis}

Results are expressed as means for each of the groups. Statistical analysis was done using Graphpad prism 8, with values of $p<0.05$ being considered as statistically significant.

\section{Results}

\section{Green synthesis of Momordica charantia nanoparticles}

The green synthesis of Momordica charantia nanoparticles (a) bitter melon ( $M$. charantia) plant (b) silver nitrate solution (c) mixture of silver nitrate and bitter melon aqueous solution after 5 min (dark green coloration) (d) synthesis of $M$. charantia nanoparticles after
$24 \mathrm{~h}$ indicated by light brown coloration are presented in Fig. 1.

\section{Characterization of Momordica charantia nanoparticles}

The graph of the UV-Visible spectrum of the M. charantia nanoparticles indicates that the nanoparticles have a maximum absorbance at a wavelength of about $430 \mathrm{~nm}$ at the three different concentrations that were evaluated. The surface morphology of the newly synthesized nanoparticles at different magnification $(100 \mu \mathrm{m}, 80 \mu \mathrm{m}$ and $50 \mu \mathrm{m})$ using scanning electron microscopy (SEM) are described in our previous study [19]. (a)

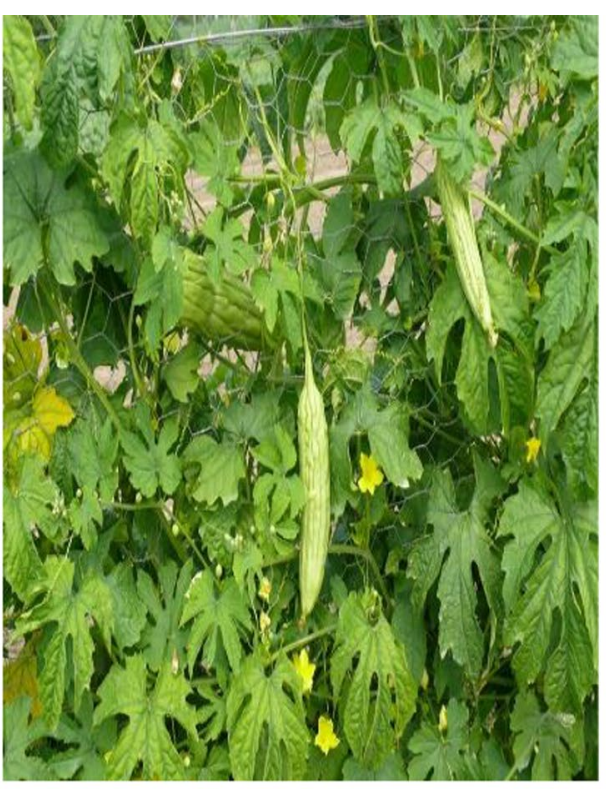

(b)
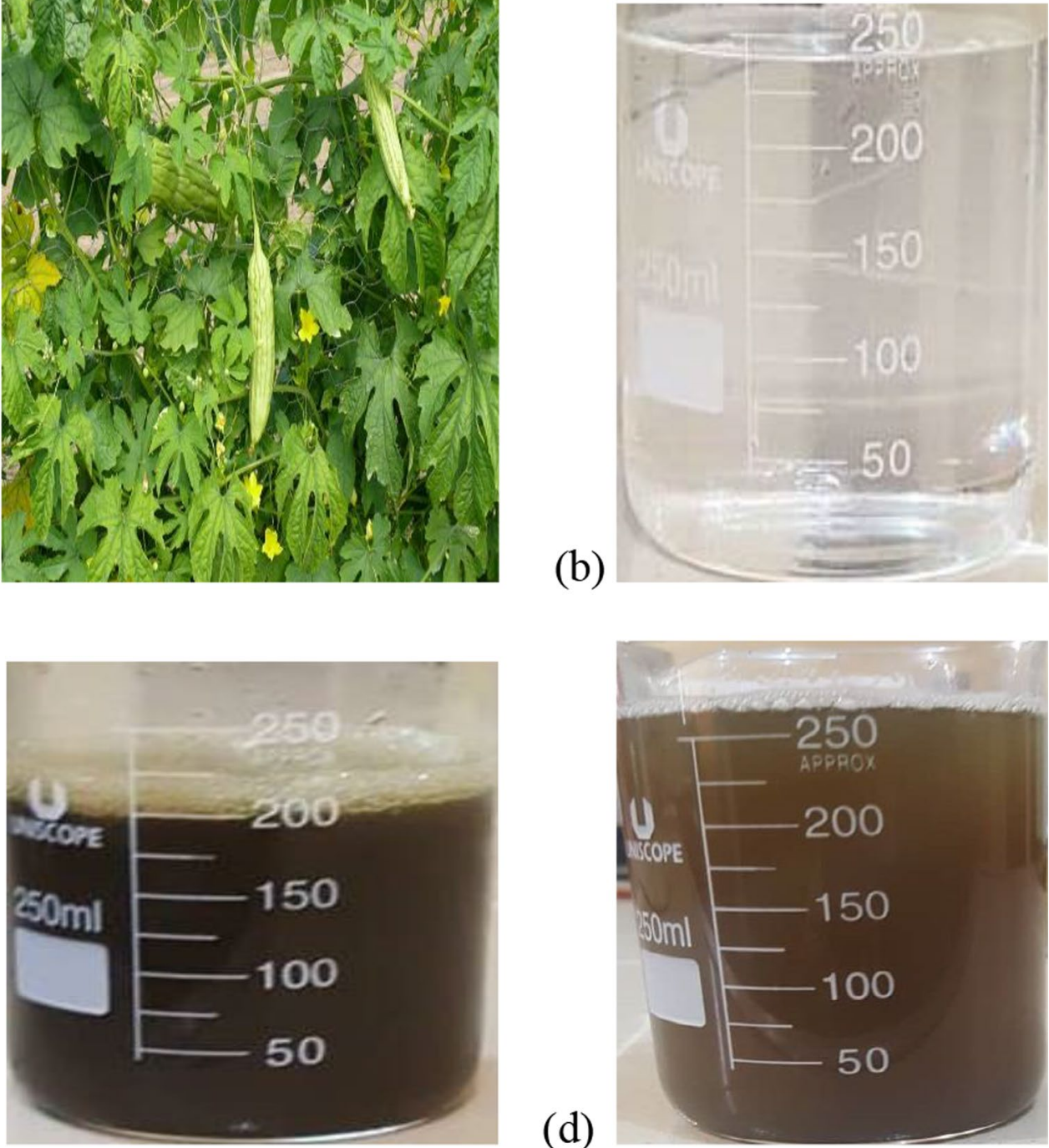

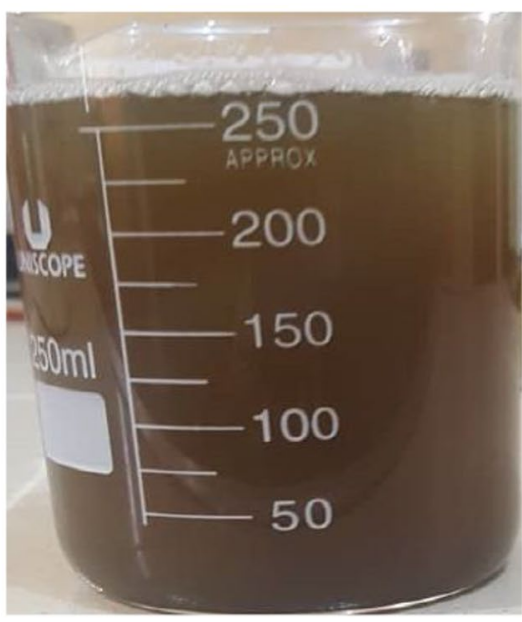

(d)

Fig. 1 Green synthesis of M. charantia nanoparticles. Picture of a M. charantia leave $\mathbf{b}$ silver nanoparticles (c) and $\mathbf{d}$ mixture of silver nitrate and bitter melon aqueous solution after $5 \mathrm{~min}$ 
Level of fasting blood glucose (FBS) before and after treatments

The FBS of all groups except the control, rose up to a level above $250 \mathrm{mg} / \mathrm{dl}$ after STZ (65 mg/kg) induction, which signifies the onset of diabetes (Table 2). After eleven (11) days of treatment, a significant reduction $(p<0.05)$ in the blood glucose level was observed in the M. charantia nanoparticles $(50 \mathrm{mg} / \mathrm{kg}), M$. charantia crude extract $(100 \mathrm{mg} / \mathrm{kg})$, silver nitrate $(10 \mathrm{mg} / \mathrm{kg})$ and metformin $(100 \mathrm{mg} / \mathrm{kg})$ treated groups.

\section{Effect of oral administration of $M$. charantia nanoparticles on mitochondrial biogenesis markers}

The expression of the PGC- $1 \alpha$ gene was significantly downregulated $(p<0.05)$ in diabetic group relative to control group. Administration of metformin, M. charantia nanoparticles $(50 \mathrm{mg} / \mathrm{kg})$ and $M$. charantia extract $(100 \mathrm{mg} / \mathrm{kg})$ upregulated the mRNA expression of PGC$1 \alpha$ in the pancreas of STZ-induced rats (Fig. 2a). The expression of the AMPK gene was significantly downregulated $(p<0.05)$ in the diabetic rats relative to the control rats. Oral administration of $M$. charantia nanoparticles $(50 \mathrm{mg} / \mathrm{kg})$ significantly upregulated the $(p<0.05)$ AMPK expression (Fig. 2b). Figure 2c below shows the effects of oral administration of $M$. charantia nanoparticles on PPAR $\Upsilon$ in the pancreas of STZ induced diabetic rats. A significant down regulation of PPAR $\Upsilon$ in diabetic group compared to control group. The expression of the PPAR $\Upsilon$ gene was significantly upregulated $(p<0.05)$ in treatment groups relative to the diabetic group. Figure $2 \mathrm{~d}$ below shows the effects of oral administration of $M$. charantia nanoparticles on GSK-3 $\beta$, one of the protein kinases implicated in the progression of diabetes. As seen in the bar chart, over-expression $(p<0.05)$ of GSK-3 $\beta$ is observed in diabetes control, relative to control. All treatment groups, however down-regulated the expression of GSK-3 $\beta$ in the pancreas of diabetic rats.

\section{Effect of oral administration of $M$. charantia nanoparticles on inflammatory genes}

The effects of oral administration of $M$. charantia nanoparticles, metformin, $M$. charantia extract and silver nitrate are illustrated as bar chart in Fig. 3a. There is significant over-expression $(p<0.05)$ of TNF- $\alpha$ in diabetic group relative to control group. The expression of the TNF- $\alpha$ gene was significantly upregulated $(p<0.05)$ in groups treated with $M$. charantia nanoparticles $(50 \mathrm{mg} / \mathrm{kg})$ and $M$. charantia extract $(100 \mathrm{mg} / \mathrm{kg})$ relative to control group. Figure $3 \mathrm{~b}$ below shows the effects of administered $M$. charantia nanoparticles on the proinflammatory cytokines IL- $1 \beta$ in the pancreas of STZinduced diabetic rats. Significantly, over-expression of IL- $1 \beta$ was observed in diabetic group when compared to control group. However, a significant down-regulation of IL- $1 \beta$ was observed in treatment groups when compared to diabetic group.

\section{Effect of oral administration of $M$. charantia on PI3K/AKT insulin signaling pathway}

Figure 4a below shows the effect of oral administration of $M$. charantia nanoparticles $(50 \mathrm{mg} / \mathrm{kg})$, metformin $(100 \mathrm{mg} / \mathrm{kg})$, M. charantia $(100 \mathrm{mg} / \mathrm{kg})$ on the pancreas of STZ-induced diabetic rats. There was significant downregulation $(p<0.05)$ of PI3K mRNA expression in diabetic group compared to control group. The treatment groups ( $M$. charantia nanoparticles $(50 \mathrm{mg} / \mathrm{kg})$, metformin $(100 \mathrm{mg} / \mathrm{kg})$, M. charantia $(100 \mathrm{mg} / \mathrm{kg}))$, however significantly upregulated $(p<0.05)$ the expression of PI3K in diabetic rats. Figure 44 below shows the effects of oral administration of $M$. charantia nanoparticles $(50 \mathrm{mg} / \mathrm{kg})$, metformin $(100 \mathrm{mg} / \mathrm{kg})$, M. charantia $(100 \mathrm{mg} / \mathrm{kg})$ on the pancreas of STZ-induced diabetic rats. There was significant downregulation $(p<0.05)$ of AKT mRNA expression in diabetic group compared to control group. The treatment groups $(M$. charantia nanoparticles $(50 \mathrm{mg} / \mathrm{kg})$, metformin $(100 \mathrm{mg} / \mathrm{kg}), M$.

Table 2 Effect of M. charantia nanoparticles $(50 \mathrm{mg} / \mathrm{kg})$, M. charantia crude extract $(100 \mathrm{mg} / \mathrm{kg})$, silver nitrate $(10 \mathrm{mg} / \mathrm{kg})$ and metformin $(100 \mathrm{mg} / \mathrm{kg})$ on the glucose levels of the experimental rats

\begin{tabular}{|c|c|c|c|c|}
\hline \multicolumn{5}{|c|}{ Fasting blood sugar levels of the rats on different days } \\
\hline Treatments & Before STZ induction & $\begin{array}{l}72 \mathrm{~h} \text { After STZ } \\
\text { induction }\end{array}$ & 6th day of treatment & 11 th day of treatment \\
\hline D. control & $97 \pm 5.78$ & $271 \pm 1.17$ & $261 \pm 3.44^{\mathrm{a}}$ & $258 \pm 7.67^{\mathrm{a}}$ \\
\hline Control & $101 \pm 2.4$ & $98 \pm 1.01$ & $103 \pm 6.12$ & $89 \pm 2.53$ \\
\hline $\mathrm{STZ}+\mathrm{S} . \mathrm{N}(10 \mathrm{mg} / \mathrm{kg})$ & $88 \pm 8.23$ & $275 \pm 5.50$ & $195 \pm 2.11^{b}$ & $170 \pm 5.24^{b}$ \\
\hline STZ + M.C SNPs (50 mg/kg) & $115 \pm 1.04$ & $277 \pm 0.45$ & $79 \pm 3.46^{b}$ & $65 \pm 1.73^{b}$ \\
\hline STZ+ Metformin (100 mg/kg) & $107 \pm 4.27$ & $271 \pm 4.89$ & $88 \pm 6.43^{b}$ & $73 \pm 1.01^{b}$ \\
\hline $\mathrm{STZ}+\mathrm{M} \cdot \mathrm{C}(100 \mathrm{mg} / \mathrm{kg})$ & $101 \pm 4.45$ & $272 \pm 1.57$ & $108 \pm 1.88^{b}$ & $84 \pm 1.06^{b}$ \\
\hline
\end{tabular}

${ }^{a}$ Statistical difference to control $(p<0.05)$ while ${ }^{\mathrm{b}}$ statistical difference to Diabetic control $(p<0.05)$. Results are expressed in mean \pm SEM, $n=7$ 


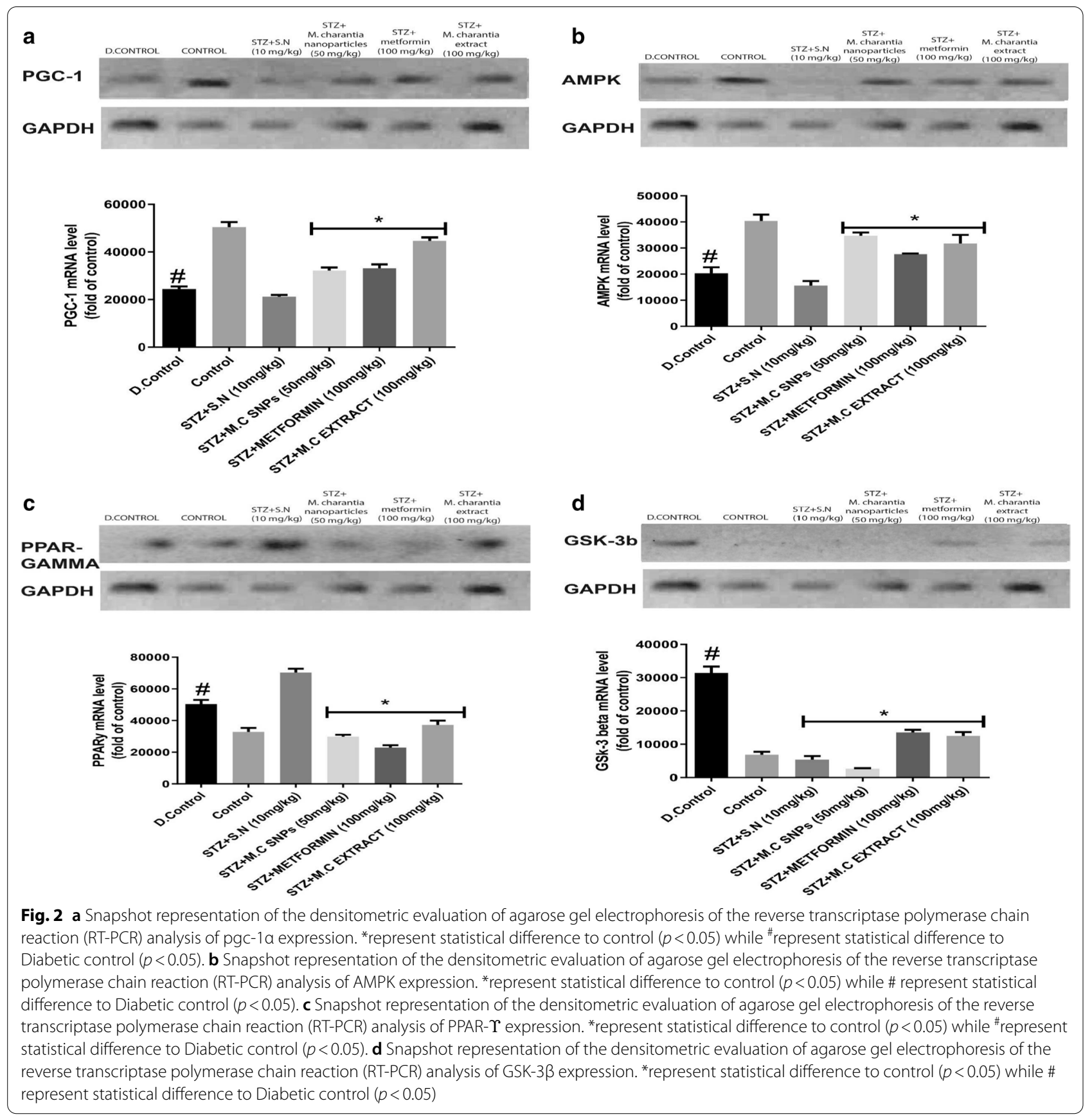

charantia $(100 \mathrm{mg} / \mathrm{kg}))$, however significantly upregulated $(p<0.05)$ the expression of AKT in diabetic rats. The expression of the PTEN gene was significantly upregulated $(p<0.05)$ in the diabetic group relative to the control group. Drawing from observation of the results as shown in Fig. 4c. There was significant downregulation $(p<0.05)$ of PTEN gene upon oral administration of $M$. charantia nanoparticles.

\section{Effect of oral administration of $M$. charantia nanoparticles on glucose sensitivity in STZ-induced rats}

The effects of $M$. charantia nanoparticles $(50 \mathrm{mg} / \mathrm{kg})$, metformin $(100 \mathrm{mg} / \mathrm{kg})$, M. charantia extract $(100 \mathrm{mg} /$ $\mathrm{kg}$ ) on insulin in STZ induced diabetic rats is shown Fig. 5a. Oral administration of $M$. charantia nanoparticles $(50 \mathrm{mg} / \mathrm{kg})$, metformin $(100 \mathrm{mg} / \mathrm{kg})$, M. charantia extract $(100 \mathrm{mg} / \mathrm{kg})$ significantly up-regulated insulin gene after the duration of treatment. In untreated 


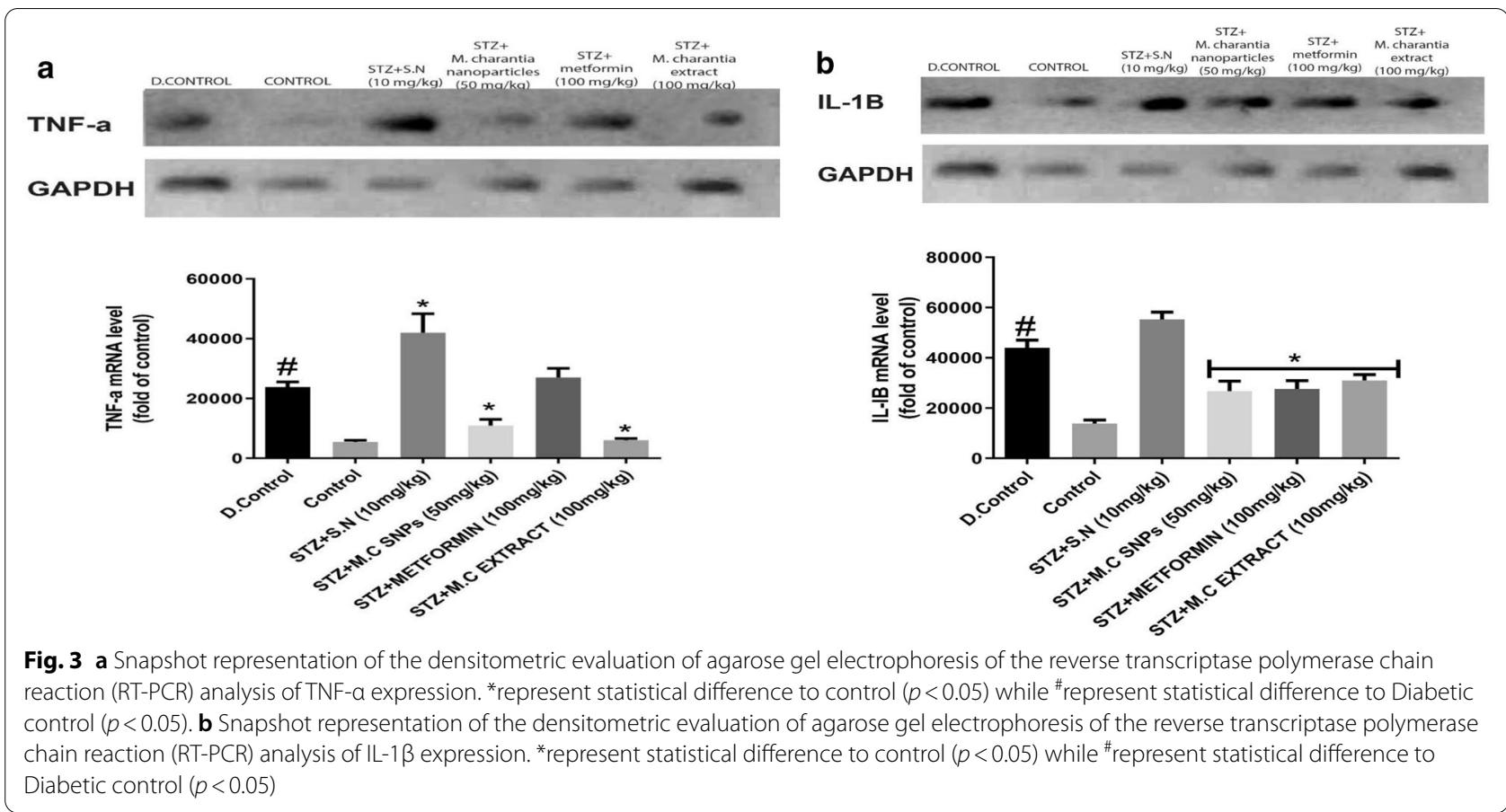

diabetes-induced rats (diabetes control), a significant under-expression $(p<0.05)$ of GLUT-2 was observed in diabetic group when compare to control group (Fig. 5b). Oral administration of $M$. charantia nanoparticles $(50 \mathrm{mg} / \mathrm{kg})$, metformin $(100 \mathrm{mg} / \mathrm{kg})$, and $M$. charantia plant extract $(100 \mathrm{mg} / \mathrm{kg})$ significantly over-expressed $(p<0.05)$ GLUT-2 mRNA in diabetic rats.

\section{Discussion}

Diabetes mellitus (DM) is one of the major leading causes of death around the globe, and its complications continues to have devastating effect on both adults and young men. The use of nanoparticles as vehicle for drug delivery to target site in biological system has gained worldwide recognition as an effective and efficacious method of targeting specific organ in drug delivery. After the synthesis of the silver nanoparticles, its characterization using SEM analysis revealed tubular clusters of silver nanoparticles with uneven surface morphologies and dimensions. FTIR spectroscopy results revealed intense bands around 3690.1, 3280.1, 2922.2, 2851.4, 1543.1, 1625.1, 1401.5, 131.95 and 1028.7 which corresponds with $\mathrm{O}-\mathrm{H}, \mathrm{N}-\mathrm{H}$, $\mathrm{C}-\mathrm{H}, \mathrm{C}=\mathrm{C}, \mathrm{C}-\mathrm{O}$ stretches. This indicates the possible role of phenol, flavonoids and amine functional groups in stabilizing the nanoparticles [19]. The diabetic status of the STZ-induced experimental rats was confirmed through FBS; and the oral administration of $M$. charantia nanoparticles $(50 \mathrm{mg} / \mathrm{kg}$ ) and $M$. charantia crude extract $(100 \mathrm{mg} / \mathrm{kg})$ to the diabetic rats was able to lower the FBS of the treated rats over the course of eleven (11) days. With this in mind, it is obvious that the $M$. charantia has glucose lowering effects.

The significant role of mitochondria dysfunction in diabetes has attracted attention in recent years because mitochondria organelle plays a large role in maintaining cellular metabolic balance [25-27]. Several key genes have been recognised as modular of mitochondria biogenesis including PGC- $1 \alpha$, and other downstream proteins $[28,29]$. The PGC- $1 \alpha$, a transcriptional co-regulation factor, is the major regulator of mitochondria biogenesis and it functions by activating different transcriptional factors including the NRFs to induce a number of genes involved in mitochondria proliferation [30]. Studies involving rats' model have demonstrated the down-regulation of PGC- $1 \alpha$ mRNA expression in diabetic states [11], and this was also confirmed in the present studies after diabetic induction of experimental rats. In the current study, the treatment groups which include $M$. charantia extract, $M$. charantia nanoparticles and the metformin were able to modulate the dysregulated gene by significant upregulation of PGC- $1 \alpha$ mRNA expression, which signifies the restoration of the mitochondria functions. Aside the pivotal role played by PGC- $1 \alpha$ in maintaining the significant function of mitochondria organelles, AMPK, one of the protein kinases involved in pathogenesis of diabetes also plays essential role in mitochondria biogenesis by antagonizing decreased in cellular ATP [31, 32]. Previous study has demonstrated that an 

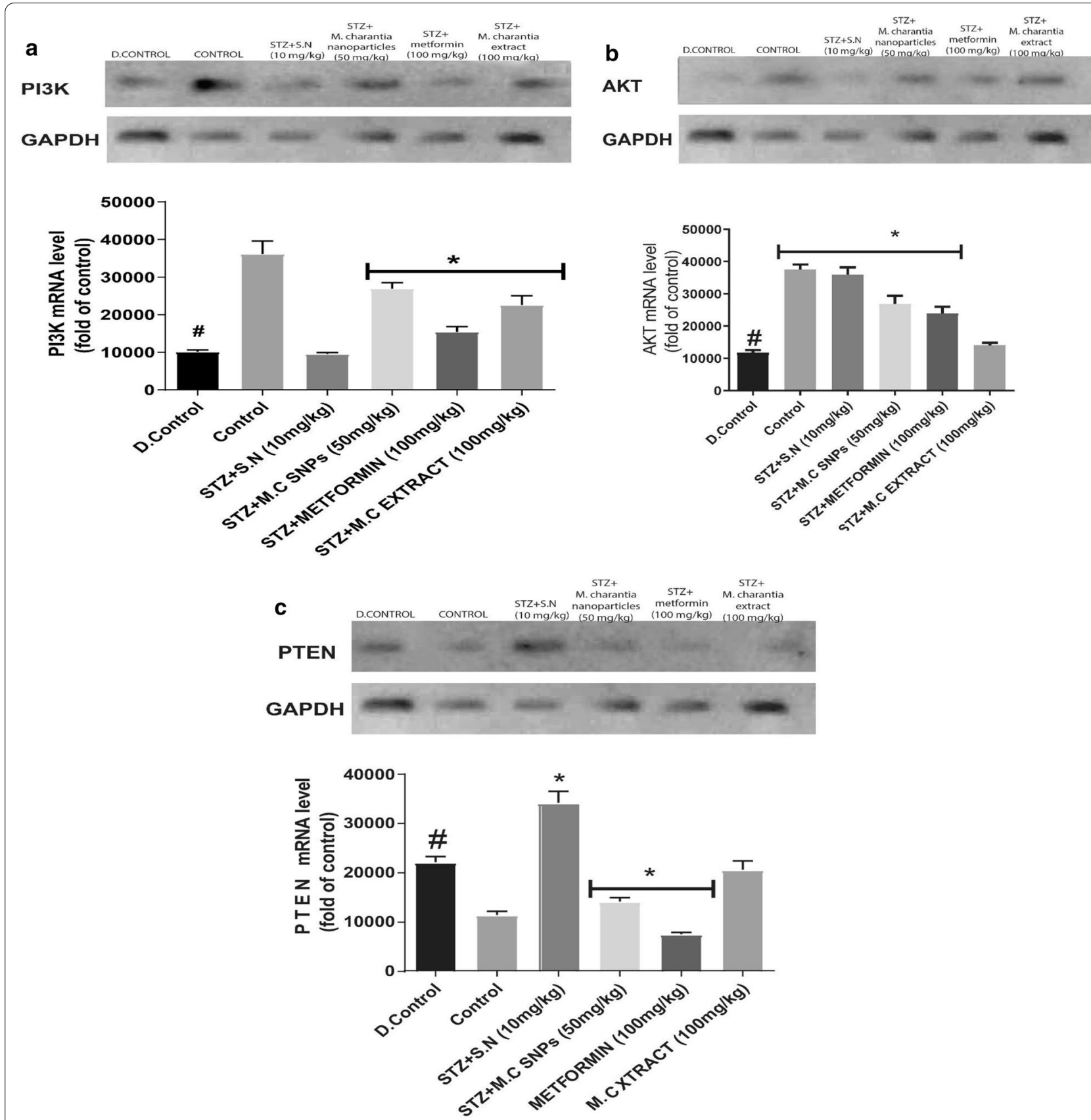

Fig. 4 a Snapshot representation of the densitometric evaluation of agarose gel electrophoresis of the reverse transcriptase polymerase chain reaction (RT-PCR) analysis of PI3K expression. ${ }^{*}$ represent statistical difference to control $(p<0.05)$ while "represent statistical difference to Diabetic control $(p<0.05)$. b Snapshot representation of the densitometric evaluation of agarose gel electrophoresis of the reverse transcriptase polymerase chain reaction (RT-PCR) analysis of AKT expression. * ${ }^{*}$ represent statistical difference to control $(p<0.05)$ while \# represent statistical difference to diabetic control $(p<0.05)$. $\mathbf{c}$ Snapshot representation of the densitometric evaluation of agarose gel electrophoresis of the reverse transcriptase polymerase chain reaction (RT-PCR) analysis of PTEN expression. * represent statistical difference to control $(p<0.05)$ while \#represent statistical difference to diabetic control $(p<0.05)$

increase in the activity of AMPK induces the expression of PGC-1 $\alpha$ through phosphorylation [33]. Hence, investigation of the downstream regulator of PGC-1 $\alpha$ in IR and impaired mitochondria biogenesis is of significance important [34]. Our results showed that treatment of diabetic rats with charantia nanoparticles up-regulated the mRNA expression of AMPK in the pancreatic tissue. This observation corroborates with results obtained from a 


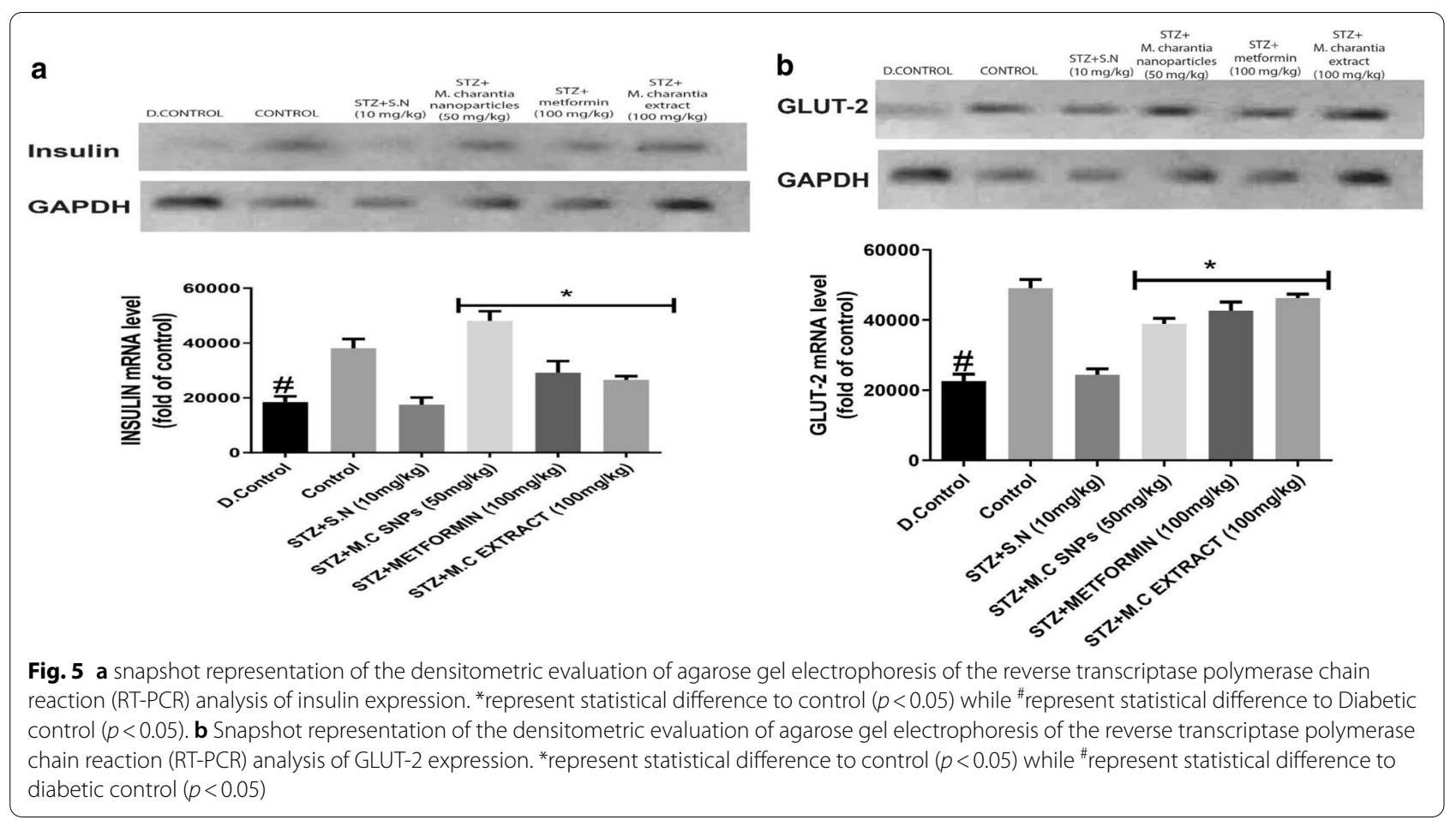

single study involving the treatment of T2DM and obesity with standard antidiabetic drug pioglitazone [35].

In mitochondrial dysfunction, the expression of peroxisome proliferator-activated receptor- $\Upsilon$ (PPAR $\Upsilon$ ) is dysregulated; this gene is known to coordinate the energy metabolism, catabolism of fatty acid (fatty acid oxidation), induction of oxidative stress, and metabolic shift towards glucose breakdown (glycolysis) [36], and all of which are believed to make significant contribution to the development of IR and diabetes. A number of studies have shown that there is alteration of mitochondria function in patients living with diabetes as a result of increased oxidative stress [37, 38]. Previous studies have demonstrated that antidiabetic agents increase the expression of PPAR $\Upsilon$, replicated mitochondria DNA copy number, upregulated the regulators responsible for mitochondria biogenesis as well as modulated fatty acid oxidation. It is evidence from our current study that $M$. charantia nanoparticles restored the function of mitochondria in diabetic rats through the upregulation of PPAR $\Upsilon$ pancreatic mRNA expression.

It is also worth mentioning that glycogen synthase kinase- $3 \beta$ (GSK-3 $\beta$ ) contributes largely to biogenesis, motility, permeability of mitochondria [39]. In addition to the critical role played by GSK-3 $\beta$ in the onset and progression of diseases including DM [40], phosphorylation of the kinase GSK-3 $\beta$ acts as an upstream regulator to decrease the expression of PGC-1 $\alpha$ [41]. Drawing from this explanation, it is obvious that phosphor-inactivation of GSK-3 $\beta$ is necessary for improving the function of the mitochondria. As shown in this study, the mRNA expression of GSK-3 $\beta$ was upregulated in diabetic rats, and GSK-3 $\beta$ mRNA expression was repressed after treatment of the rats with $M$. charantia nanoparticles. The evidence that $M$. charantia nanoparticles downregulated the mRNA expression of GSK-3 $\beta$ validates its mitochondrial biogenesis effect through the modulation of aforementioned PGC- $1 \alpha$ mRNA in the power house of the cells.

Some studies revealed an increase in inflammation of tissues in diabetic rats through the overexpression of both pro-inflammatory and inflammatory cytokines [42]. These cytokines are known for their unwanted effect on insulin signalling and sensitivity of glucose. The upregulation of TNF- $\alpha$ and IL- $1 \beta$ genes correlates with impaired insulin signalling pathways (through phosphorylation of protein kinase B) and T2DM [43]. The anti-inflammatory properties of $M$. charantia nanoparticles was shown through the repression of TNF- $\alpha$ and IL- $1 \beta$ mRNA. Hence, $M$. charantia nanoparticles ameliorated inflammation in the pancreas of STZ-induced rats.

To elucidate the antidiabetic effect of $M$. charantia nanoparticles, insulin, Glut2 and key genes modulating PI3K/AKT insulin signaling pathway were taken into consideration. The PI3K, AKT and PTEN genes are important modulator of PI3K/AKT pathway; while PI3K and Akt activate PI3K/Akt signalling pathway, the PTEN 
gene acts as a negative regulator of PI3K/Akt pathway. Studies have demonstrated that PI3K/AKT pathway correlate to the metabolism of glucose, which is important for the increased uptake of glucose by insulin in the tissue $[44,45]$. Dysregulation of this pathway through repression of AKT, PI3K and overexpression of PTEN is peculiar to diabetic models [46]. Plant extract that activates PI3K/AKT pathway has the tendency of ameliorating IR [47]. Our study showed that $M$. charantia nanoparticles could activate the insulin signaling pathway by reversing the downregulation of PI3K and AKT, and upregulation of PTEN mRNA expression in the pancreas of diabetic induced rats. Also, it is worth noting that oral administration of $M$. charantia nanoparticles promote insulin secretion, glucose uptake and metabolism through the up-regulation of insulin and Glut2 mRNA expression in pancreatic $\beta$ cells. Our result is consistent with an in vivo study demonstrating that crude extract of $M$. charantia could increase the secretion of insulin from endocrine pancreatic $\beta$ cells [48].

The data obtained from this study showed that $M$. charantia nanoparticles promote mitochondria biogenesis, insulin secretion and glucose metabolism, as well as alleviate inflammation in the pancreas of STZ-induced diabetic rats through upregulation of PGC- $1 \alpha$, PPAR , AKT, PI3K, Glut2, insulin, AMPK mRNA expression and repression of GSK-3 $\beta$, TNF- $\alpha$, IL- $1 \beta$ and PTEN mRNA expression.

\section{Conclusions}

The current findings demonstrated that in addition to the already established hypoglycemic effects of $M$. charantia on model rats, the use of $M$. charantia nanoparticles significantly reduced the glucose level in STZ-induced rats at a lower dose $(50 \mathrm{mg} / \mathrm{kg})$ relative to $M$. charantia extract $(100 \mathrm{mg} / \mathrm{kg})$. Administration of $M$. charantia nanoparticle promoted mitochondria biogenesis, reversed inflammation and glucose insensitivity in the pancreas of STZ-induced diabetic rats through modulation of PGC-1 $\alpha$ and other key genes.

\section{Abbreviations}

DM: Diabetes mellitus; IR: Insulin resistance; STZ: Streptozotocin; FBS: Fasting blood sugar; PGC-1a: Peroxisome Proliferator -activated receptor gamma coactivator 1 alpha; Nrf2: Nuclear Respiratory factor 1; Nrf2: Nuclear Respiratory factor 2; ERRa: Estrogen-Related receptor alpha; PPART: Peroxisome proliferator-activated receptor- $\Upsilon$; GSK-3ß: Glycogen Kinase 3ß; AMPK: AMP-activated protein kinase; T2DM: Type Il diabetes mellitus; JAK: Janus kinase; STAT: Signal transducer and activator of transcription; PI3K: Phosphatidylinositol-3-kianse; AKT: Protein kinase B; RT-PCR: Reverse transcriptase polymerase chain reaction; CDNA: Complementary DNA; SEM: Scanning electron microscopy; PTEN: Phosphatase and tensin homolog; GLUT-2: Glucose transporter 2; TNF-a: Tumour necrosis factor alpha; IL-1 $\beta$ : Interleukin 1 beta.
}

\section{Authors' contributions}

OOE: Conceptualization, Methodology, reviewing and editing, supervision. OCA: methodology, formal analysis, writing. Ol: writing —original draft preparation, writing - review and editing, formal anaylsis. All authors read and approved the final manuscript.

\section{Funding}

This research received no external funding.

\section{Availability of data and materials}

All data generated or analysed during the current study are included in this published article.

\section{Declarations}

\section{Ethical approval and consent to participate}

The experiments were performed in accordance with the National Guidelines for Experimental Animal Welfare and with approval of the Animal Welfare and Research Ethics Committee at the Federal University of Technology, Akure, Nigeria. The Committee reference number is not available.

\section{Consent for publication}

Not applicable.

\section{Competing interest}

The authors declare that they have no known competing interest.

Received: 2 July 2021 Accepted: 30 September 2021

Published online: 09 November 2021

\section{References}

1. Wu Y, Ding Y, Tanaka Y, Zhang W (2014) Risk factors contributing to type 2 diabetes and recent advances in the treatment and prevention. Int J Med Sci 11:1185-1200. https://doi.org/10.7150/ijms.10001

2. Fan W (2017) Epidemiology in diabetes mellitus and cardiovascular disease. Cardiovasc Endocrinol 16:8-16. https://doi.org/10.1097/XCE.00000 00000000116

3. Shi Y, Hu FB (2014) The global implications of diabetes and cancer. Lancet 383:1947-1948. https://doi.org/10.1016/S0140-6736(14)60886-2

4. Caballero AE, Ceriello A, Misra A, Aschner P, McDonnell ME, Hassanein M, Ji L, Mbanya JC, Fonseca VA (2020) COVID-19 in people living with diabetes: an international consensus. J Diabetes Complications 9:107671. https://doi.org/10.1016/j.jdiacomp.2020.107671

5. Amira REB, Samy AH, Abeer AA, Yehia AH, Tarek MM (2016) Saponins and their potential role in diabetes mellitus. Diabetes Manag 7(148-1):5

6. Elekofehinti OO, Onunkun AT, Olaleye TM (2020) Cymbopogon citratus (DC.) Stapf mitigates ER-stress induced by streptozotocin in rats via down-regulation of GRP78 and up-regulation of Nrf2 signaling. J Ethnopharmacol 262:113-130

7. Nelson DL, Cox MM (2008) Lehninger principles of biochemistry, 5 edn. W. H. Freeman, New York

8. Brand MD, Orr AL, Perevoshchikova IV, Quinlan CL (2013) The role of mitochondrial function and cellular bioenergetics in ageing and disease. Br J Dermatol 69:1-8. https://doi.org/10.1111/bjd.12208

9. Bertholet AM, Delerue T, Millet AM, Moulis MF, David C, Daloyau M et al (2016) Mitochondrial fusion/fission dynamics in neurodegeneration and neuronal plasticity. Neurobiol Dis 90:3-19

10. Mishra P, Chan DC (2016) Metabolic regulation of mitochondrial dynamics. J Cell Biol 4:379-87. https://doi.org/10.1083/jcb.201511036

11. Fang WJ, Wang CJ, He Y, Zhou YL, Peng XD, Liu SK (2017) Resveratrol alleviates diabetic cardiomyopathy in rats by improving mitochondrial function through PGC-1 a deacetylation. Acta Pharmacol Sin 1:59-73. https://doi.org/10.1038/aps.2017.50

12. Villena JA (2015) New insights into PGC-1 coactivators: redefining their role in the regulation of mitochondrial function and beyond. FEBS $J$ 4:647-672. https://doi.org/10.1111/febs.13175 
13. Bogacka I, Xie H, Bray GA, Smith SR (2005) Pioglitazone induces mitochondrial biogenesis in human subcutaneous adipose tissue in vivo. Diabetes 54:1392-1399

14. Sergi D, Naumovski N, Heilbronn L, Abeywardena M, O'Callaghan N et a (2019) Mitochondrial (Dys) function and insulin resistance: from pathophysiological molecular mechanisms to the impact of diet. Front Physiol. https://doi.org/10.3389/fphys.2019.00532

15. Antoun G, McMurray F, Thrush AB, Patten DA, Peixoto AC, Slack RS et al (2015) Impaired mitochondrial oxidative phosphorylation and supercomplex assembly in rectus abdominis muscle of diabetic obese individuals. Diabetologia 58:2861-2866. https://doi.org/10.1007/s00125-015-3772-8

16. Chen J, Wong HS, Leong PK, Leung HY, Chan WM, Ko KM (2017) Ursolic acid induces mitochondrial biogenesis through the activation of AMPK and PGC-1 in C2C12 myotubes: a possible mechanism underlying its beneficial effect on exercise endurance. Food Funct 7:2425-2436. https:// doi.org/10.1039/c7fo00127d

17. Yuan X, Gang W, You Y, Huang Y, Lee H, Dong M, Jun L, Hu T, Zhang H, Zhang C, Zhou H, Ye R, Qi X et al (2016) Rutin ameliorates obesity through brown fat activation. FASEB J. https://doi.org/10.1096/ff.201600459RR

18. Yang K, Chen Z, Gao J, Shi W, Li L, Jiang S, Hu H, Liu Z, Xu D, Wu LH (2017) The key roles of GSK-3 $\beta$ in regulating mitochondrial activity. Cell Physiol Biochem 44:1445-1459. https://doi.org/10.1159/000485580

19. Elekofehinti OO, Oyedokun VO, Iwaloye O, Lawal AO, Ejelonu OC (2021) Momordica charantia silver nanoparticles modulate S OCS/JAK/STAT and P13K/Akt/PTEN signalling pathways in the kidney of streptozotocininduced diabetic rats. J Diabetes Metab Disord 66:1-16

20. Akhtar N, Khan BA, Majid A, Khan S, Mahmood T, Gulfishan J et al (2011) Pharmaceutical and biopharmaceutical evaluation of extracts from different plant parts of indigenous origin for their hypoglycemic responses in rabbits. Acta Pol Pharm 6:919-925

21. Hasan I, Khatoon S (2012) Effect of Momordica charantia (bitter gourd) tablets in diabetes mellitus: type 1 and Type 2. Prime Res Med 2:72-74

22. Nahar MK, Zarina-Zakaria U, Fazlul-Bari MD (2015) Green synthesis of silver nanoparticles using Momordica charantia fruit extracts. Adv Mat Res. https://doi.org/10.4028/www.scientific.net/amr.1109.35

23. Abdelwahed W, Degobert G, Stainmesse S, Fessi H (2006) Freeze-drying of nanoparticles: formulation, process and storage considerations. Adv Drug Deliv Rev 58:1688-1713

24. Oluyede DM, Lawal AO, Adebimpe MO et al (2021) Biochemical and molecular effects of naringenin on the cardiovascular oxidative and proinflammatory effects of oral exposure to diesel exhaust particles in rats. Air Qual Atmos Health. https://doi.org/10.1007/s11869-021-00991-2

25. Pinti MV, Fink GK, Hathaway QA, Durr AJ, Kunovac A, Hollander JM (2019) Mitochondrial dysfunction in type 2 diabetes mellitus: an organ-based analysis. Am J Physiol Endocrinol Metab 2:268-285. https://doi.org/10. 1152/ajpendo.00314.2018

26. Gonzalez-Franquesa A, Patti ME (2017) Insulin resistance and mitochondrial dysfunction. Adv Exp Med Biol 982:465-520. https://doi.org/10. 1007/978-3-319-55330-6_25

27. Di Meo S, lossa S, Venditti P (2017) Skeletal muscle insulin resistance: role of mitochondria and other ROS sources. J Endocrinol 1:15-42. https://doi. org/10.1530/JOE-16-0598

28. Jornayvaz FR, Shulman Gl (2010) Regulation of mitochondrial biogenesis. Essays Biochem 47:69-84. https://doi.org/10.1042/bse0470069

29. Sergio R, Isabel T, Iván M, Ángel L (2020) PGC-1a, inflammation, and oxidative stress: an integrative view in metabolism. Oxid Med Cell Longev. https://doi.org/10.1155/2020/1452696

30. Wu Z, Puigserver P, Andersson U, Zhang C, Adelmant G, Mootha V, Troy A, Cinti S, Lowell B, Scarpulla RC, Spiegelman BM (1999) Mechanisms controlling mitochondrial biogenesis and respiration through the thermogenic coactivator PGC-1. Cell 1:115-124. https://doi.org/10.1016/ S0092-8674(00)80611-X

31. Finck BN, Kelly DP (2006) PGC-1 coactivators: inducible regulators of energy metabolism in health and disease. J Clin Invest 16(61):5-22

32. Handschin C, Spiegelman BM (2006) Peroxisome proliferator-activated receptor gamma coactivator 1 coactivators, energy homeostasis, and metabolism. Endocr Rev 27:728-735
33. Jager S, Handschin C, St-Pierre J et al (2007) AMP-activated protein kinase (AMPK) action in skeletal muscle via direct phosphorylation of PGC-1 alpha. Proc Natl Acad Sci 104:12017-12022

34. Musi N, Fujii N, Hirshman MF et al (2001) AMP-activated protein kinase (AMPK) is activated in muscle of subjects with type 2 diabetes during exercise. Diabetes 50:921-927

35. Bandyopadhyay GK, Yu JG, Ofrecio J et al (2006) Increased malonylCoA levels in muscle from obese and type 2 diabetic subjects lead to decreased fatty acid oxidation and increased lipogenesis; thiazolidinedione treatment reverses these defects. Diabetes 55:2277-2285

36. D’Alessandro A, El Kasmi KC, Plecitá-Hlavatá L, Ježek P, Li M, Zhang H et al (2017) Hallmarks of pulmonary hypertension: mesenchymal and inflammatory cell metabolic reprogramming. Antioxid Redox. https://doi.org/ 10.1089/ars.2017.7217

37. Lee TW, Bai KJ, Lee TI et al (2017) PPARs modulate cardiac metabolism and mitochondrial function in diabetes. J Biomed Sci 24:5. https://doi. org/10.1186/s12929-016-0309-5

38. Patterson AD, Shah YM, Matsubara T, Krausz KW, Gonzalez FJ (2012) PPARa-dependent induction of uncoupling protein 2 protects against acetaminophen-induced liver toxicity. Hepatol 56:281-290

39. Jang YJ, Son HJ, Choi YM, Ahn J, Jung CH, Ha TY (2017) Apigenin enhances skeletal muscle hypertrophy and myoblast differentiation by regulating Prmt7. Oncotarget 8:78300-78311. https://doi.org/10.18632/ oncotarget.20962

40. Iwaloye O, Elekofehinti OO, Oluwarotimi EA et al (2020) Insight into glycogen synthase kinase-3 $\beta$ inhibitory activity of phyto-constituents from Melissa officinalis: in silico studies. In Silico Pharmacol 8:2. https://doi.org/ 10.1007/s40203-020-00054-X

41. Sun Q, Jia N, Li X, Yang J, Chen G (2019) Grape seed proanthocyanidins ameliorate neuronal oxidative damage by inhibiting GSK-3 $\beta$-dependent mitochondrial permeability transition pore opening in an experimental model of sporadic Alzheimer's disease. Aging 12:4107-4124. https://doi. org/10.18632/aging.102041

42. Mahmoud AM, Ashour MB, Abdel-Moneim A, Ahmed OM (2012) Hesperidin and naringin attenuate hyperglycemia-mediated oxidative stress and proinflammatory cytokine production in high fat fed/streptozotocininduced type 2 diabetic rats. J Diabetes Complications 6:483-490

43. Bastard JP, Piéroni L, Hainque B (2000) Relationship between plasma plasminogen activator inhibitor 1 and insulin resistance. Diabetes Metabol Res Rev 3:92-201

44. Chen Y, Wu Y, Yang Y et al (2018) Transcriptomic and proteomic analysis of potential therapeutic target genes in the liver of metformin-treated sprague-dawley rats with type 2 diabetes mellitus. Int J Mol Med 6:3327-3341. https://doi.org/10.3892/ijmm.2018.3535

45. Nana W, Tiegang L, Ping H (2016) The effect of tianmai xiaoke pian on insulin resistance through PI3-K/AKT signal pathway. J Diabetes Res 2016:1-8

46. Maosheng L, Huilin L, Hengxia Z, Miao S, Deliang L (2020) Effects of hydroxysafflor yellow A on the PI3K/AKT pathway and apoptosis of pancreatic $\beta$-cells in type 2 diabetes mellitus rats. Diabetes Metab Syndr Obes 13:1097-1107. https://doi.org/10.2147/DMSO.S246381

47. Sun H, Liu X, Long SR, Wang T, Ge H, Wang Y, Yu S, Xue Y, Zhang Y, Li X, Li W (2019) Antidiabetic effects of pterostilbene through PI3K/Akt signal pathway in high fat diet and STZ induced diabetic rats. Eur J Pharmacol 59(1):72526. https://doi.org/10.1016/j.ejphar.2019.172526

48. Singh N, Gupta M, Sirohi P, Varsha S (2008) Effects of alcoholic extract of Momordica charantia. (Linn) whole fruit powder on the pancreatic islets of alloxan diabetic albino rats. J Environ Biol 29(1):101-6

\section{Publisher's Note}

Springer Nature remains neutral with regard to jurisdictional claims in published maps and institutional affiliations. 